
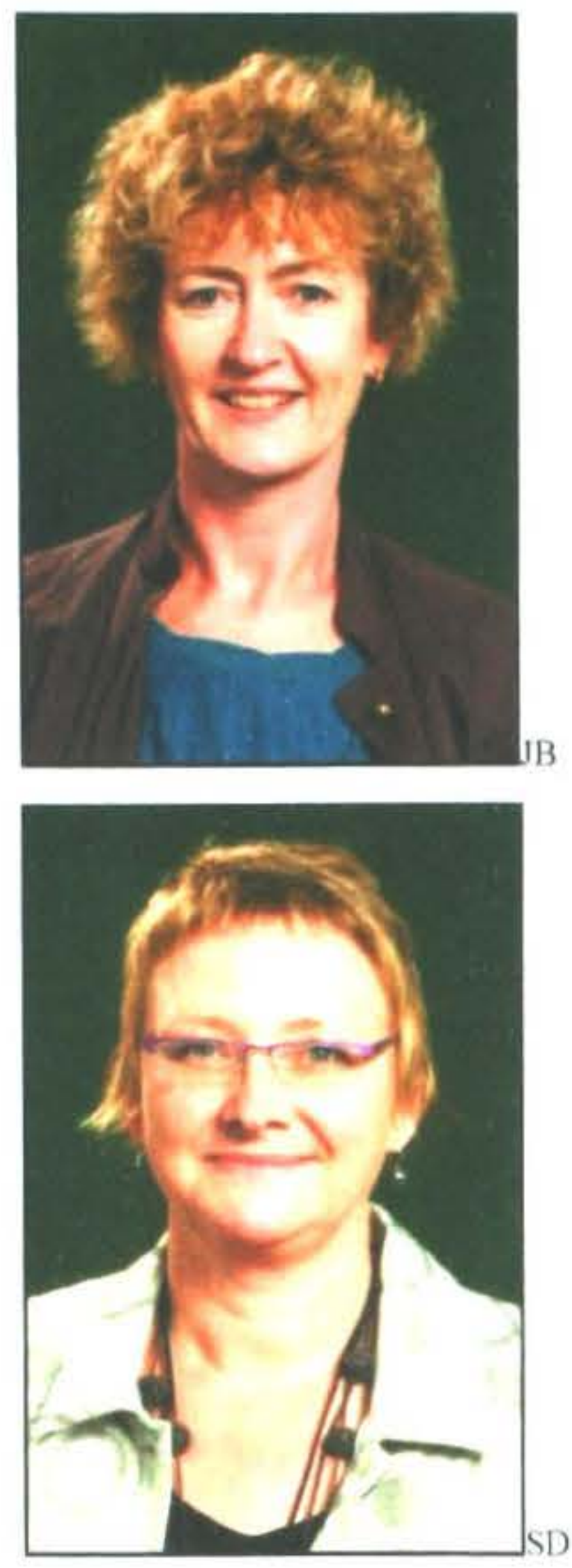

\section{MAPPING THE PRODUCTIVITY TERRAIN}

\author{
Jane Bryson, Michelle Renton, Sally \\ Davenport, Urs Daellenbach
}

Victoria Management School, Victoria University of Wellington

Shirley Leitch, Judy Motion

Faculty of Commerce, University of Wollongong

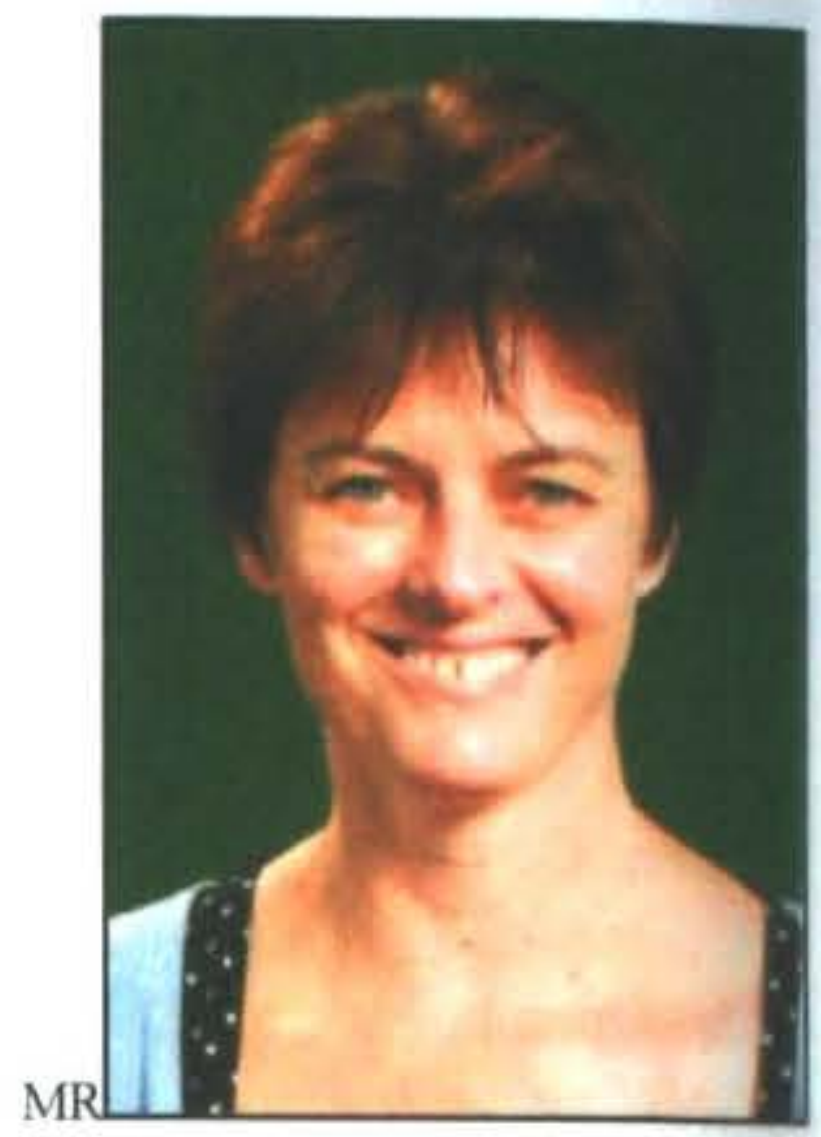

Abstract

Starting from a broad discussion of the range of debate and interest in productivity, our focus narrows to explore the territory of firm-level productivity. We review how productivity at firm-level has been defined and studied. We then turn our attention to the New Zealand context reviewing recent attempts by several government policy agencies to map the terrain and drivers of productivity: Within these we find some consensus, but also some divergence which we discuss. Finally we identify gaps in knowledge about productivity at the firm-level, and we outline how our FRST funded 'Building our productivity' research project aims to study these gaps in order to improve our map of the productivity terrain.

\section{Introduction}

Productivity means many things to many people - and therein lies the challenge for useful exploration of the topic: is it one concept or several? Or is it one multi faceted concept? Or is the construction of the concept evolving?

Twenty years ago Pritchard. Jones, Roth. Stuebing \& Ekeberg (1988) identified serious issues in the productivity literature, in particular the different approaches to measuring and thus conceptualising productivity and confusion over the level of analysis being used. They noted that "in popular literature, one sees the term productivity used to refer to a unit of analysis ranging from the individual to entire countries" (p. 339). These concerns are still salient today. Indeed scanning the literature in the reference list of this paper one will find that the term productivity is used variously to refer to a wide range of levels (and to similar levels with differing nomenclature) including: national; sector or industry; enterprise or organisation or firm or work place; workgroup, and individual.

Tuttle (1983, cited in Pritchard et al 1988) explains the different approaches to measurement as being due to the perspective of those doing the measuring. Specifically he suggests five views: those of the economist, engineer, accountant, manager and industrial/organizational psychologist. For instance it is suggested that the economist tends to examine the performance of large units such as whole industries or countries; whilst the psychologist tends to focus on the performance of the individual and the human resource system. Nonetheless, all of these groups have feted productivity since Taylor's scientific management theories and Ford's mass production line changed the manufacturing world. Embedded in this are assumptions which favour short run efficiency for productivity growth and beliefs that processes, technology and individual labour effort are key. Largely productivity is a means to an end. It is pursued in order to increase competitive advantage of a 
nation, an industry or an organisation, and thus the prosperity of its beneficiaries.

At the simplest level, productivity can be defined as the efficiency with which volumes of measured inputs are converted into volumes of measured outputs (Janssen and McLoughlin, 2008). Two measurements of productivity are commonly used. The first, labour productivity, (LP) is a measure of outputs produced by a volume amount of labour effort. Statistics New Zealand (2008) measure LP as an index of valued added in constant prices, divided by an index of labour inputs ( $\mathrm{LP}=\mathrm{V} / \mathrm{L})$. A commonly used empirical measure of labour productivity is sales per employee, (Guthrie, 2001; Guest, Michie, Conway and Sheehan, 2003; Mason, 2005), although output per hour worked, and output per worker are also used (see paragraph below). The second measure is Multi or (Total) Factor Productivity (MFP). The measure of MFP used by Statistics New Zealand follows the OECD's guidelines outlined in the OECD manual Measuring Productivity (2001). Put simply, MFP is a measure of Value Added (VA), a function of a measure of technical shifts over time $A(t)$, multiplied by a production function of labour (L) and Capital (K) inputs, $(V=A(t) \times f(L, K))$. But even these are not without significant conceptual and practical ambiguity. For example, Griliches (1979) outlines a range of issues associated with measuring productivity growth including the effects of price changes on sales per employee calculations, the difficulties of accurately assessing physical or R\&D capital values, and the impact of R\&D investments on a firm's own sales as well as R\&D spillovers to competitors and related industries.

Diverse arrays of measures are used to investigate productivity related research questions. Productivity can be assessed using economy wide measures, enabling aggregate comparisons across countries of both labour and multi factor productivity such as those found in the OECD standings. Measurements chosen may also vary according to the argument one wants to make. Keep, Mayhew and Payne (2006) illustrate this point citing two policy documents issued in December 2005 by the UK HM Treasury in which one argues the UK has poor productivity performance on the basis of an output per hour worked measure, and the other argues significant progress in productivity using an output per worker measurement.

In New Zealand, the emphasis on the business or market sector (the measured sector), enables official statistics to be used for industry level productivity analysis, although the recent development of a prototype longitudinal dataset (IBULDD) by Statistics New Zealand has encouraged exploration of microeconomic questions surrounding firm dynamics, including productivity (Fabling, Grimes, Sanderson and Stevens, 2008). The focus in this paper is on firm-level productivity, although we sound a further note of caution that the literature variously refers to firm-level concerns as: enterprise, organisation, firm, work place, workgroup, and individual.

\section{Understanding Firm-level Productivity}

It is essential to understand productivity at the individual enterprise level, as a large fraction of aggregate productivity growth is driven by what happens within individual firms (Scarpetta, Hemmings, Tressel and Woo, 2002). Ahn (2001) analyses aggregate productivity growth as the sum of two separate processes, firstly, the reallocation of resources arising from the expansion and contraction of existing firms as well as the entry and exit of individual firms within a given industry, and secondly, the changes in productivity within individual firms due to increasing or decreasing efficiency. These points are discussed in greater detail below:

\section{Reallocation of Resources within an Industry}

Studies incorporated into this literature review suggest a wide dispersion of productivity rates within any given industry (Bartlesman and Doms, 2000; Ahn 2001). Reports from within New Zealand establish a great variation in firm performance within industries, with low (high) productivity industries containing high (low) performing firms (Fabling, Sanderson and Stevens, 2008). This dispersion is important because future industry performance appears to be related to current firm-level outcomes. It has been shown that those firms who are highly productive today (using both labour and multi factor measures) are likely to be highly productive tomorrow (Bartlesman and Doms, 2000). In New Zealand around $62 \%$ of firms remain in the same labour productivity (value added/hours worked) quartile after one year, and $43 \%$ after four years. These drop further to $33 \%$ after nine years (Law, Buckle and Hyslop, 2006).

A portion of productivity growth is attributable to firm entry and exit from different industries. Substantial numbers of firms enter and exit from industries each year with those leaving tending to have lower aggregate productivity levels, and those entering having lower productivity initially, moving to or past the average productivity level of incumbents by their second or third year (Fabling, Sanderson and Stevens, 2008). While labour productivity is enhanced by the exit of low productivity units especially in mature industries, Law et al (2006) suggest that within firm productivity dynamics dominate the effects of firm entry and exit.

\section{Within Firm Multi Factor Productivity Effects}

A major area of work relating to firm-level productivity is identifying and measuring factors and elements that influence levels of multi (or total) factor productivity. A number of factors have been examined in the literature and these are discussed below. It is noted however, that researchers have been unable to quantify the importance 
of individual elements, or attribute causal effects to changes in productivity.

\section{Leadership and Managerial Ability}

Good leadership and management practices have been identified as a key influence on overall productivity within firms. While much of what makes good leadership and management remains elusive, elements previously studied include operational and monitoring practices, the setting of targets and the provision of incentives. Studies using these four areas have found that higher management scores in these four areas were correlated with higher total factor productivity (Bloom and Van Reenen, 2006; Griffith, Haskel \& Neely, 2006). In an advance on Bloom \& Van Reenen's inter firm comparisions, Griffith et al (2006) compared productivity of different branches within the same firm and still found that $40 \%$ of productivity differences were accounted for by management practices.

However, identifying the intangible factors that make up good leadership and management has proven difficult to do. These intangibles are said to be key to the differences between high and low productivity firms. Having a management and leadership team with entrepreneurial/ innovative flare, who are able to identify opportunities and move their organisations to take advantage of them has been put forward as an important characteristic for increasing workplace productivity (Workplace Productivity Working Group, 2004). Additionally, having an organisational leadership and management which is visible, available, builds open communications and is concerned with creating a culture of quality has been posited as characteristic of a highly productive work place (Ryan, 2008).

\section{Innovation}

An organisation's ability to innovate is recognised as crucial in driving productivity growth (Proctor, 2008). In 2005, Statistics New Zealand reported increasing productivity as the second most common reason (behind increasing revenue) for organisations to adopt innovative practices, with $81 \%$ of innovating businesses reporting productivity improvements to be a motivating factor. Griliches (1988: 19) states that "R\&D has been a significant contributor to past productivity growth and [...] that basic research has an even stronger effect". He also argues that R\&D spillovers (ideas and information about materials, processes and products/services that impact the productivity of the R\&D endeavours of others) are present and prevalent (Griliches, 1992).

Four major types of innovations have been identified (Proctor, 2008), firstly, in organisational or managerial processes through for example, re-engineering work flows, secondly, in operational processes, such as in the adoption of new technologies, thirdly, in marketing products or services, such as finding more efficient distribution systems, and lastly, in improving product or service offerings themselves.

Key traits of innovative organisations include having an innovation orientation, involving an internal knowledge structure composed of a learning philosophy, strategic direction and a culture that believes in the importance of innovation. These three elements help to define and direct organisational strategies and actions towards innovation enabling competencies (Sigauw, Simpson and Enz, 2006). Other characteristics of innovative firms include that they network both regionally and more widely within and outside of their value chains (Gellyneck, Vermeire and Viane, 2007), are internationally oriented (Davenport, 2005) and they access new ideas from a wide range of sources including internal and external research and development, new and existing staff, customers, conferences, advisors, competitors, suppliers and many others (Doczi, 2008).

\section{Information Communications Technology}

While a direct causal link between ICT use and firmlevel productivity remains unproven (Ahn, 2001), exploitation of ICT technology has been shown to help firms be more productive by raising overall TFP (Lee, Schneider and Brinkley, 2007) or through leveraging the benefits of other strategic resources (Powell and DentMicallef, 1995). ICT enables greater levels of decentralisation which becomes increasingly important as information becomes easier to transmit. It appears that actual ICT investment matters less than how it is invested within the wider context of the firm, for example, greater productivity results when ICT's adopted match both the technological needs and skills of staff within an organisation.

\section{Internationalisation}

Firms with international connections appear to have a clear productivity advantage over purely domestic firms, with exposure to competition and international trade playing an important role in selecting high productivity firms (Ahn, 2001; Fabling, Sanderson and Stevens, 2008; Kafouras, Buckley, Sharp and Wang, 2008). Over a wide range of countries, studies generally show that exporters have higher productivity than non-exporters. Two hypotheses for this have been put forward, firstly, the self selection of more productive firms into the export market and secondly, firms learning by exporting with knowledge flowing from international buyers and competitors helping to improve the post entry performance of export starters, i.e. exporting makes firms more productive (Wagner, 2007). Initial work suggests that the performance advantage exporters have exists prior to their entering exporting (Wagner 2007, Fabling, Sanderson and Stevens, 2008). 


\section{Foreign Ownership}

Ahn (2001) identified ownership structure as an important determinant of firm-level productivity and studies from both New Zealand and the United Kingdom have found that foreign owned firms have higher productivity levels than domestic firms (Fabling, Sanderson and Stevens, 2008). Lee, Schneider and Brinkley (2007), report on a number of studies suggesting that UK based US multinationals are more productive than UK owned firms, particularly in the wholesale and retail sectors, in which the US productivity revival was felt most strongly. They reason that the superior organisational design of US firms which allow for a greater impact from ICT use, are exported to UK based affiliates, giving US owned firms a productivity advantage over both UK owned firms and multinationals owned by other countries.

\section{Within firm Labour Productivity Effects}

\section{The Use of SHRM Practices}

The case for an association between SHRM practices and performance (in general, but including increasing productivity levels) is based on two arguments linked to the Resource Based View (RBV) of the firm. The first is that the effective deployment of human resources offers one of the most powerful bases for competitive advantage (Barney, 1995). The second is that the effective deployment of human resources depends on the application of a distinctive combination of practices, described as bundles (or systems) of practices (Barney and Wright, 1998; Pfeffer, 2005). Combined, these enhance the firm's competitive position by creating superior 'human capital' resources, in parallel with the product/market strategy the firm pursues at any given time (Koch and McGrath, 1996). Many authors including Huselid (1995), Fabling and Grimes (2007) and Tamkin. Cowling and Hunt (2008) find that systems of high performance work place practices influence productivity, turnover and corporate financial performance.

A caveat on this relationship exists. Koch and McGrath (1996) suggest that positive and significant effects on labour productivity when utilising sophisticated HR planning, recruitment and selection are more pronounced for those organisations which are capital intensive with a high ratio of fixed assets to employees. Fabling and Grimes (2007) point out that firms operating in a market in which individual flair drives both quality and output may find that choice of HR practices central to performance. However, for low tech firms with fixed coefficient technology operating in undifferentiated commodity markets, there may be little if any advantage in adopting potentially costly HR practices. Nevertheless, and with this caveat in place, bundles of HRM practices that have been seen to aid productivity include: performance pay for employees, firm specific employee acquisition and training (Huselid, 1995; Chen,
Liaw, and Lee, 2003; Fabling \& Grimes, 2007) labour relations emphasising co-operation and dispute resolution, emphasis on quality of work life, quality circles and labour management teams (Huselid, 1995) and low turnover rate (Guthrie, 2001, Scarpetta, Hemmings, Tressel and Woo, 2002).

However, evidence supporting the role of SHRM in increasing firm-level productivity is somewhat equivocal. Wood (in Guest et al., 2003) comments that the quality of the research base supporting the relationship between HRM and performance is relatively weak. Two studies have found either nil or negative results for the role of HRM practices in increasing productivity. Guest et al., report nil results for nine measures of HRM practices when assessing improvements in labour productivity using objective measures (some improvements were found when using subjective measures). Richard and Johnson (2001) found no main effects for SHRM on increasing productivity, but did find interaction effects between SHRM practices and capital intensity on increasing productivity. The RBV provides a possible explanation for these differing results, suggesting that the effects of productivity gains on performance will depend on the extent to which such practices are new vs. widespread within a set of competitors. Thus, gains from implementing novel practices may only flow through to performance for early adopters whereas late adopters can only hope for achieving competitive parity (Powell, 1992). Overall, there is an acceptance that use of high performance work place systems increases productivity for organisations whose competitive strategy is based on high value/ high quality outputs. A recently published longitudinal (22 year) study of the impact of HR and operational management practices on company productivity (308 companies) reports that "consistent with SHRM theory we found performance benefits from empowerment and extensive training, with the adoption of teamwork serving to enhance both. In contrast, none of the operational practices were directly related to productivity nor did they interact with other practices in ways fully consistent with the notions of integrated manufacturing or lean production" (Birdi, Clegg, Patterson, Robinson, Stride, Wall and Wood, 2008, p. 468).

\section{ICT and Labour Productivity}

In an analysis of the relationship between investment in ICT use, labour productivity and workplace reorganisation, Bertschek and Kaiser (2004) found that labour productivity significantly increased in firms who underwent organisational change to take advantage of investments in ICT. The authors claim this finding is attributable to the complementarities between the various input factors (including adoption of ICT) and workplace reorganisation.

\section{Social Capital and Cohesion}

Productivity growth depending on the application of new forms of work organisation through job redesign, multi- 
skilling, multi-tasking, the more extensive use of team working, flatter management structures and the delegation of responsibility to individuals and teams, can lead to a working environment characterised by a high level of change and discontinuity (Coates, 2007). Researchers working in the area of social capital and cohesion believe organisations which have developed higher levels of internal social capital are more likely to both adopt high performance work practices and make them work. Building social capital within an organisation focuses on increasing levels of established norms such as trust and reciprocity within organisations to both encourage information flows and build individual resilience in the face of organisational change.

Programmes designed to promote the building of social capital and cohesion have recently been adopted in European countries including Finland. Germany and the Netherlands, One objective of these programmes is to create sustainable workplace productivity growth through optimal utilisation of the labour force. The focus is on improving the quality of working life within organisations, by providing greater opportunities for employee development, to exert influence at work, and to strengthen internal co-operation and trust within the work place community (Alasonini, Heikkilä, Ramstad and Ylöstalo, 2008; Pot and Vaas, 2008). As yet, the effectiveness of these programmes remains untested.

\section{Measures}

Firm-level productivity is generally measured using longitudinal multi data sets (LMDs). The use of LMDs offer large and statistically representative sets of sector and/or firm-level data, generally collected and maintained by government agencies. These data sets have the advantage of enabling measurement of changes in productivity over time, and when data collected is comparable, allow for comparisons of productivity between countries. Difficulties with these data sets include the fact that most concentrate on dynamics and productivity change within the manufacturing industries as measurement of productivity within service industries is more difficult (Ahn, 2001: Keep et al, 2006). Even within the manufacturing setting, assessing productivity change is problematic because the interplay between changing production processes, quality, the cost/value of inputs and outputs, as well as the other factors noted above make it impossible to uniquely interpret changes as real productivity improvements or deteriorations (see Griliches. 1979 for a lengthy discussion of these measurement problems).

Thus for researchers working within the strategic management and organisational behaviour frameworks, productivity research is often more exploratory in nature. Questions seeking to explain the heterogenous nature of productivity within a given industry, drivers of productivity improvements within firms and the role of high performance management systems in improving organisational productivity are questions requiring methodologies that supply a rich texture of detailed information. Methodologies used in answering these questions include case studies, and in-depth interviews, while survey methodologies are often also employed to improve generalisability.

However, as Keep et al (2006) note, at firm-level in the United Kingdom private sector businesses prefer to focus on metrics other than productivity, e.g., profitability, returns on capital investment, earnings per share, etc.

\section{New Zealand Policy Agencies and Firm-level Productivity Drivers}

In New Zealand, a number of government agencies have published papers focusing on creating economic transformation through improving productivity, including The Treasury, the Department of Labour and the Ministry of Economic Development. These papers incorporate many of the learnings gained from the international experience, and two of them, the Department of Labour (WPWG 2004 and Ryan, 2008) and Treasury (Janssen and McLoughlin, 2008), have separately discussed drivers of firm-level productivity. Their papers reflect the agencies differing view points, with Treasury adopting a macro-level approach identifying five drivers, and the Department of Labour a micro-level focus to identify and discuss seven drivers internal to organisations. The two sets of drivers are summarised below:

\section{The Five Treasury Drivers}

Enterprise- the ongoing need to maintain and improve New Zealand's entrepreneurial regulatory framework in which the promotion of competition remains an important consideration of policy, barriers remain low, the effects of the tax system is understood and the regulatory environment both improves and remains fit for purpose.

Innovation- firms increasingly leverage off external sources of ideas, both internationally and from New Zealand's public research base.

Skills - seek ways to improve the education and skill level of all New Zealanders, but particularly the disadvantaged groups who make up the 'tail' of educational outcomes. This requires improving the quality of pre-school, school, tertiary and on the job training post-school.

Investment - with greater use of innovation and by encouraging entrepreneurship, investment opportunities within New Zealand will improve.

Access to natural resources -requires the development of an integrative framework to ensure resources are used productively while achieving environmental goals. 


\section{The Seven Department of Labour (Workplace Productivity Working Group) Drivers}

Building leadership and management - Strong leadership includes identifying new opportunities and inspiring others to pursue those opportunities, while good management includes adapting organisations to changing environments

Creating Productive Workplace Cultures - high performing workplaces are founded on a strong workplace culture with motivated and engaged employees. Firms can cultivate such an environment by acknowledging the contribution of employees, rewarding participation and good ideas, developing healthy and respectful relationships within the workplace and promoting a sense of shared goals and values.

Encouraging Innovation and the Use of Technology Creating new products and services or just doing things better are all vital ways to achieve firm growth. The major challenge is to harness the capability to exploit and extract value from innovation processes, services or technologies.

Investing in people and skills - ongoing investment in foundation, technical, supervisory and managerial skills can help the productivity of New Zealand firms. A key is to match the potential and talents of New Zealanders with the skills needed in the workforce.

Organising work - firms need to assess and adapt their structures and business practices and the way they carry out their work on an ongoing basis, to ensure that the activities that create value are aligned with each other, the overall business strategy and that they function effectively.

Networking and collaboration -significant productivity gains are to be made by improving the exchange of knowledge, information and ideas through both formal and informal networks.

Measuring what matters - effective measurement is essential in assessing the value to a firm of investing in other workplace drivers. Measurement needs to be linked to strategy objectives, needs to be tailored to an individual firm and be balanced in its approach.

The difference in approaches between the two agencies may have implications for government policy, and concerns have recently been raised by Ryan (2008), who suggests that policy responses to productivity issues have focused on investing in education and encouraging innovation and technology use, with less investment in work organisation, leadership, management and creating positive workplace cultures. While this could result from the differences in macro and micro viewpoints of policy advisors, it is also likely that the greater emphasis on education, innovation and technology use is due to these factors being easy to identify, with investment effects being relatively easy to measure. Less focus on work organisation, leadership, management and creating positive workplace cultures may be due to the difficulty of identifying how productivity improvements using these factors can be achieved, and because productivity is not of itself, necessarily a major concern for many organisational managers. Similar concerns have been raised in the UK policy environment by Mayhew and Neely (2006).

\section{Gaps and Key Messages}

Some gaps and key points arise from the literature surveyed in this review, including:

- The conceptual and practical ambiguity surrounding productivity is reflected in the range of measures used, the range of levels of analysis, and ultimately in the fact that that although many governments agree on the importance of productivity a range of 'policy levers' have failed to significantly improve productivity.

- Understanding what drives firm-level productivity is important, not just in assessing and improving the performance of individual firms, but for improving economic growth for the nation as a whole.

While labour productivity is important in itself, measurement of Multi Factor Productivity allows for a focus on improving business processes to help drive increases in productivity. These processes include elements such as organisational design and structure, governance, management practices, the use of strategic human resource management practices (SHRM), innovation and internationalisation. With the exception of SHRM practices (discussed in the following point), little research has been performed to determine how business processes impact on productivity, and on the ways in which productivity improvements can be gained through a re-organisation of them.

- Use of strategic human resource management practices can have an impact on improving levels of productivity. However, research suggests that it is the combination of practices bundled together that has the greatest effect, rather than the use of individual practices. Understanding which combinations of SHRM practices interact and how they influence firm-level productivity will have implications for improving productivity levels within firms and for the country as a whole.

After reviewing the studies incorporated into this review, it appears that the concentration on productivity related issues in academic and government literature is not apparent in the thinking of managers within individual firms. It is proposed that a disconnect exists between the way in which academic and government agencies understand productivity and the importance they attach to it, and the way in which productivity is viewed by organisational managers and the 
importance they attribute to productivity in improving firm performance.

- Understanding the complexity of what leads to productivity improvement can only be achieved by researching what happens inside organisations.

- $\quad$ Researchers should not lose sight of why we are interested in productivity - not for its own sake, but for its contribution to greater competitiveness and thus ultimately societal prosperity and well being.

\section{The Building 'Our' Productivity Project}

The Building "Our' Productivity Project is set up to research issues relating to firm-level productivity and seeks to address research gaps exposed within this review, particularly those outlined in the key messages. In doing so, the project will identify and increase knowledge about the collective ways in which New Zealand's productivity can be improved at firm-level particularly through a focus on unpacking how business processes influence multi factor productivity. By increasing understanding of these processes, in particular those that are 'collective', it is hoped that greater understanding of the ways in which improvements in MFP can be generated and sustained will be gained. For our purposes, we will adopt an approach to describing MFP as the component of value-added not explained by either capital or labour inputs, but which is attributable to improved business processes that lead to greater firm efficiency.

\section{Research Questions and Objectives}

The fundamental research question underlying the project reflects the current lack of knowledge about collective processes and their influence on productivity. It is: What is our collective productivity and how does it differ between high and medium value added firms within and between sectors? Underlying this research question are the three research objectives:

1. To identify successful collective strategies and processes for sustainably improving firm productivity.

2. To understand the attributes and value brought to collective productivity by intangible capitals such as intellectual (explicit and tacit knowledge), symbolic (identity and brands) and social (relationships and networks) capital.

3. To compare firm-level productivity in two sectors, the innovation and alliance intensive biotechnology sector, and the labour intensive food and beverage sector.

In defining these objectives, the focus on 'collective' elements of productivity and the role that intangibles (intellectual, symbolic and social capitals) play in influencing it will help address the gaps in knowledge relating to the way in which 'collective' business processes and 'collective' SHRM tools influence MFP. Previously, improvements in productivity were generally sought through either cost cutting measures, including through the reduction of staff numbers (Workplace Productivity Working Group, 2004), or by improving individual skills and skill mixes within organisations in an effort to create superior 'human capital' resources (Koch and McGrath, 1996), as shown in Figure 1 below. Now, the Building 'our' Productivity project will attempt to find longer term solutions to firm-level productivity issues which focus on collective efforts and build on the intellectual, symbolic and social capital of an organisation. Additionally, through employing a case study approach, the project will investigate whether there is a disconnection between academic and government led discussions about productivity, and the way in which productivity is viewed and valued within individual organisations.

Figure 1: Approaches to improving firm-level productivity

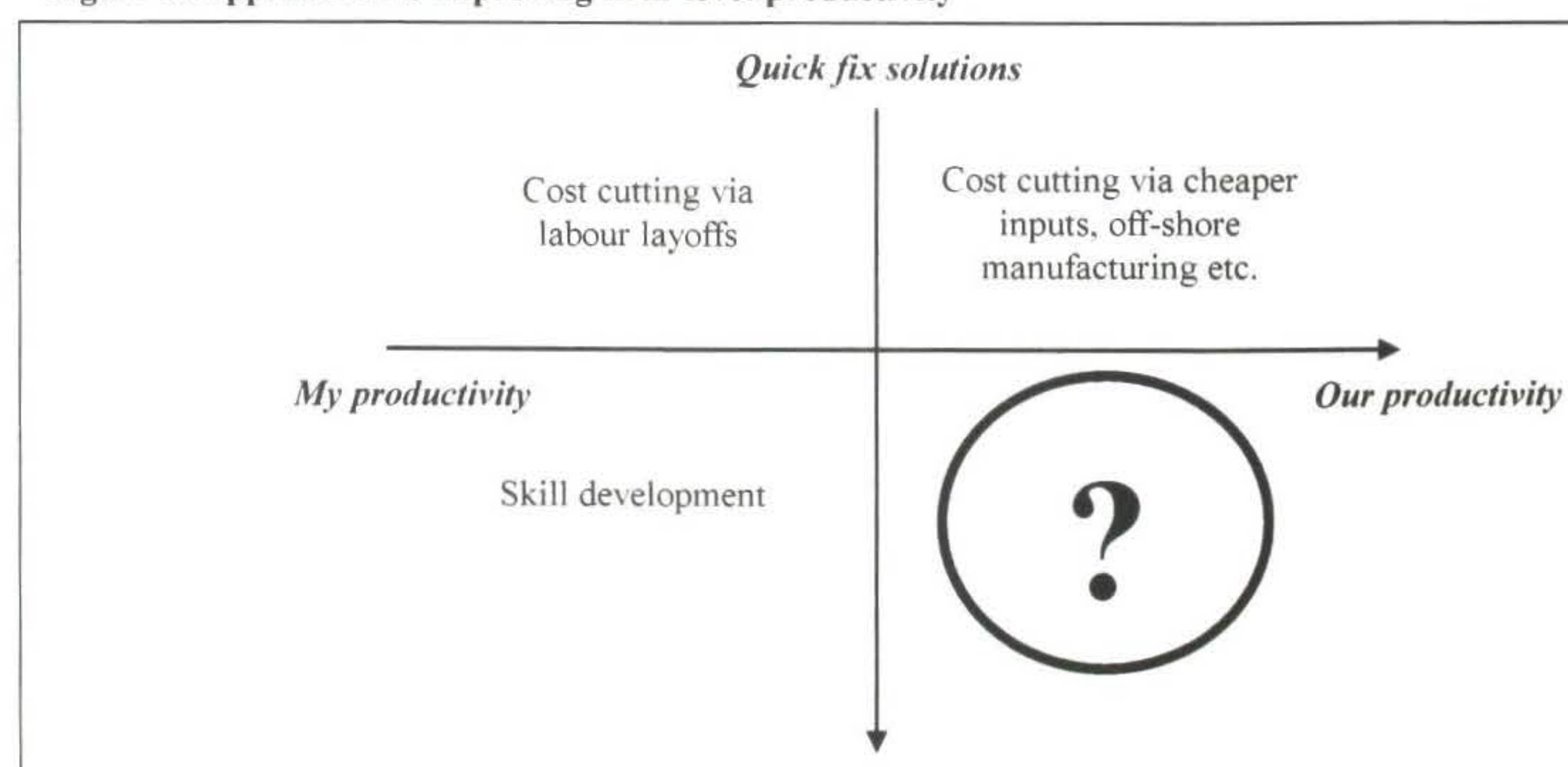

Long term (sustainable) solutions 


\section{References}

Ahn, S. (2001). Firm Dynamics and Productivity Growth: A Review of Micro Evidence from OECD Countries. OECD Economics Department Working Papers NO 297, OECD Publishing. doi: $10.1787 / 054842728775$.

Alasoini, T. Heikkilä, A. Ramstad, E. and Ylöstalo, P. (2008). High innovation practices at Finnish workplaces. International Journal of Productivity and Performance Management. 57

(6): 449-459.

Barney, J. (1995). Looking for competitive advantage. Academy of Management Executive. 9, 49-61.

Barney, J. and Wright, P. (1998). On becoming a strategic partner: the roles of human resources in gaining competitive advantage. Human Resource Management. 37: 31-46.

Bartelsman, E. and Doms, M. (2000). Understanding productivity: Lessons from Longitudinal Microdata. Journal of Economic Literature. 38(3): 569-594.

Bertschek, I. and Kaiser, U. (2004). Productivity effects of organisational change: microeconometric evidence. Management Science. 50 (3): 394-405.

Birdi, K. Clegg, C. Patterson, M. Robinson, A. Stride, C. Wall, T. D. and Wood, S. (2008.) The impact of human resource and operational management practices on company productivity: a longitudinal study. Personnel Psychology. 61. 467-501.

Bloom, N. and Van Reenen, J. (2006). Management practices, work-life balance, and productivity: a review of some recent evidence. Oxford Review of Economic Policy. 22(4) 457-482.

Bloom, N. and Van Reenen, J. (2006). Measuring and explaining management practices across firms and countries. CEPR Discussion paper No. 5581, London, Centre for Economic Policy Research, available at:

http://www.cepr.org/pubs/dps/DP5581.asp/

Cascio, W. (2006). The Economic Impact of Employee Behaviors on Organizational Performance. California Management Review. 48, 41-59.

Chen, L-H. Liaw, S. and Lee, T-Z. (2003). Using an HRM Pattern Approach to Examine the Productivity of Manufacturing Firms - An Empirical Study. International Journal of Manpower. 24, 3 299-318.
Coates, D. (2005). Ideopolis: Knowledge Cities: Working Paper 1 - What is the Knowledge Economy? The Work Foundation.

http://www.theworkfoundation.co.uk. accessed 19 August 2008.

Davenport, S. (2005). New Zealand High-Tech Business Model: Aspiraton or Anathema? Inaugural professorial lecture, Victoria University of Wellington.

Doczi, M. (2008). Innovation from Everyone and Everywhere: Developing Sustainable Innovation Capability for $21^{\text {st }}$ Century New Zealand. A discussion paper. www.dol.govt.nz. accessed 15/09/08.

Fabling, R. \& Grimes, A. (2007). HR Practices and Firm Performance: What Matters and Who Does It? Ministry of Economic Development. Occasional Paper 07/02.

http://www.med.govt.nz/templates/MultipageDoc umentTOC 29768.aspx. accessed 28 August 2008

Fabling, R. Grimes, A. Sanderson, L and Stevens, P. (2008). Some Rise by Sin and Some by Virtue fall: Firm Dynamics, Market Structure and Performance. Ministry of Economic Development. www.med.govt.nz/templates/multipageDocument TOC_34197.aspx. Accessed 12 August 2008.

Fox, J and. Smeets, V. (2008). Does Input Quality Drive Measured Differences in Firm Productivity? Unpublished Report.

Gellyneck, X. Vermeire, B. and Viaene, J. (2007). Innovation in Food Firms: Contribution of Regional Networks Within the International Business Context. Entrepreneurship \& Regional Development, 19 (May) 209-226.

Griffith, R. Haskel, J and Neely, A. (2006). Why is productivity so dispersed? Oxford Review of Economic Policy. 22(4) 513-525.

Griliches, Z. (1979). Issues in Assessing the Contribution of Research and Development to Productivity Growth. Bell Journal of Economics. 10(1): 92-116.

Griliches, Z. (1988). Productivity Puzzles and R\&D: Another Nonexplanation. The Journal of Economic Perspectives. 2 (4): 9-21.

Griliches, Z. (1992) The Search for R\&D Spillovers. Scandinavian Journal of Economics. 94. Supplement, S29-S47.

Guest, D. Michie, J. Conway, N and Sheehan, M. (2003). Human Resource Management and 
Corporate Performance in the UK. British Journal of Industrial Relations. 41(2): 291-314

Guthrie, J. (2001). High Involvement Work Practices, Turnover and Productivity: Evidence from New Zealand. Academy of Management Journal 44(1): 180-190.

Harvey, O and Harris, P. (2008). The Skills Productivity Nexus: Connecting Industry Training and Business Performance. Department of Labour. http://www.dol.govt.nz/browse-dol.asp

Huselid, M. (1995). The Impact of Human Resource Management Practices on Turnover, Productivity and Corporate Financial Performance. Academy of Management Journal. 38, 3 635-672.

Janssen, J and McLoughlin, S. (2008). New Zealand's Productivity Performance. New Zealand Treasury Productivity Paper 08/02.

Kafouras, M. Buckley, P. Sharp, J. and Wang, C. (2008). The Role of Internationalisation in Explaining Innovation Performance. Technovation, 28, 1-2, 63-74.

Keep, E. Mayhew, K and Payne, J. (2006) From skills revolution to productivity miracle - not as easy as it sounds? Oxford Review of Economic Policy. 22(4) 539-559.

Koch, M and McGrath, R. (1996). Improving Labour Productivity: Human Resource Management Policies Do Matter. Strategic Management Journal. 17 335-354.

Law, D. Buckle B and Hyslop, D. (2006). Toward a Model of Firm Productivity Dynamics. New Zealand Treasury Working Paper 06/11.

Lee, N. Schneider, P and Brinkley, I. (2007). R\&D, ICT and Productivity: An Evidence paper for the Knowledge Economy Programme. The Work Foundation.

http://www.theworkfoundation.com/research/keco nomy/kereports.aspx accessed 14 August 2008.

Mason, G. (2005). In search of High Value Added Production: How important are skills? Investigations in the Plastics Processing, Printing, Logistics and Insurance Industries in the UK. National Institute of Economic and Social Research London. http://www.niesr.ac.uk/pubs/pubs.php accessed 10 August 2008.

Mayhew, K and Neely, A. (2006). Improving productivity - opening the black box. Oxford Review of Economic Policy. 22(4) 445-456.
Nelson, R. (1981). Research on Productivity Growth and Productivity Differences: Dead Ends and New Departures. Journal of Economic Literature, XIX (September) 1029-1064.

Pfeffer, J. (2005). Producing sustainable competitive advantage through the effective management of people, The Academy of Management Executive. Vol. 19, Iss. 4; pg. 95-106.

Pot, F. and Vaas, F. (2008). Social innovation, the new challenge for Europe. International Journal of Productivity and Performance Management. 5(6): 468-473.

Powell, T. C. (1992). Strategic Planning As Competitive Advantage. Strategic Management Journal. Vol. 13, Iss. 7; pg. 551-558.

Powell, T. C. and Dent-Micallef, A. (1997). Information Technology As Competitive Advantage: The Role Of Human. Strategic Management Journal, 18, 5, pp. 375-405.

Pritchard, R. Jones, S. Roth, P. Stuebing, K and Ekeberg, S. (1988). Effects of group feedback, goal setting, and incentives on organizational productivity. Journal of Applied Psychology. 73(2) $337-358$.

Proctor, R. (2008). Inside the Black Box: Policies for Economic Growth. Ministry of Economic Development, Occasional paper 08/08. http://www.med.govt.nz/templates/MultipageDoc umentTOC 38648.aspx. accessed 13 November 2008 .

Richard, O, and Johnson, N. (2001). Strategic Human Resource Management Effectiveness and Firm Performance. International Journal of Human Resource Management 12(2): 299-310

Ryan, R. (2008). Why Workplaces Matter: The Role of Workplace Practices in Economic Transformation. Department of Labour. http://www.dol.govt.nz/browse-dol.asp

Scarpetta, S. Hemmings, P. Tressel, T. and Woo, J. (2002). The Role of Policy and Institutions for Productivity and Firm Dynamics: Evidence from Micro and Industry data, OECD Economics Working Paper 15.

Siguaw, J. Simpson, P and Enz, C. (2006). Conceptualising Innovation Orientation: A Framework for Study and integration of Innovation Research. Journal of Product Innovation Management. 23. 556-574. 
Statistics New Zealand (2005). Innovation in New Zealand: Shedding light on business practices and performance of innovating New Zealand businesses. Statistics New Zealand, Wellington.

Tamkin, P. Cowling, M. and Hunt, W. (2008). People and the Bottom Line. Institute for Employment Studies, report 448, London: UK.

Tangen, S. (2005). Professional Practice: Demystifying productivity and performance. International Journal of Productivity and Performance Management. 54, 1. 34-46.

The Workplace Productivity Working group. (2004). The Workplace Productivity Challenge: Summary Report. Department of Labour. http://www.dol.govt.nz/browse-dol.asp

Wagner, J. (2007), Exports and Productivity: A Survey of the Evidence from Firm-level Data. The World Economy.
Shirley Leitch

Dean

Faculty of Commerce

University of Wollongong

Northfields Avenue

Wollongong

NSW 2522

Australia

SLeitch@uow.edu.au

\section{Judy Motion}

Professor of Marketing and Management/School

Research Director

Faculty of Commerce

University of Wollongong

Northfields Avenue

Wollongong

NSW 2522

Australia

JMotion@uow.edy.au

\section{Authors}

Jane Bryson

Senior Lecturer

HR Management and Industrial Relations

Victoria University of Wellington

P.O. Box 600

Wellington 6140

Jane.Bryson@vuw.ac.nz

Michelle Renton

Industrial Relations Centre

Victoria Management School

Victoria University of Wellington

P.O. Box 600

Wellington 6140

Michelle.Renton@vuw.ac.nz

Sally Davenport

Professor

Head of School

Victoria Management School

Victoria University of Wellington

P.O. Box 600

Wellington 6140

Sally.Davenport@vuw.ac.nz

Urs Dallenbach

Associate Professor

Reader in Management

Victoria Management School

Victoria University of Wellington

P.O. Box 600

Wellington 6140

Urs.Daellenbach@vuw.ac.nz 